Article

\title{
Motivational physical activity intervention for psychiatric inpatients: A two phased single- cases experimental study
}

\author{
Marit Sørensen ${ }^{1}$, Marte Bentzen ${ }^{1,2}$ and Anders Farholm ${ }^{1,3}$ \\ Received: $25^{\text {th }}$ November 2020; Accepted: 29 ${ }^{\text {th }}$ June 2021; Published: $21^{\text {st }}$ November 2021
}

\begin{abstract}
Physical inactivity has been identified among leading risk factors for global mortality as well as an independent risk factor for several somatic diseases. There is consistent evidence that individuals with mental illness engage in little physical activity. Therefore, this study investigated associations between a motivational physical activity intervention in treatment for psychiatric inpatients and change in; 1) physical activity level measured by accelerometer, 2) motivation for physical activity, and 3) affect and perceived functional health status. The design was a longitudinal, two-phased multiple single-cases experiment. Seven individuals completed a baseline period and an eight-week physical activity program. The participants had high autonomous motivation and mostly positive, but mixed profiles of development. Four participants showed favourable development profiles for physical activity, one no change, and two reduced physical activity. For positive and negative affect, five had a favourable development, one no change, and one unfavourable. For health status, six had a favourable development, one no change. The intervention was feasible as part of treatment. The physical activity results reflected different physical activity histories. This highlights the importance of individualising physical activity programs in psychiatric treatment, and the use of person centered research methods that can reveal such differences.
\end{abstract}

Keywords: Motivation, exercise, self-determination theory, affect.

\section{Introduction}

Physical inactivity has been identified as the fourth leading risk factor for global mortality as well as being an independent risk factor several somatic diseases (Biswas et al., 2015; World Health Organisation (WHO), 2021). It is well established that people with severe mental illness (SMI) have increased mortality compared with the general population. Their life expectancy is reduced by around 15 - 20 years, and they display disproportionally high prevalence of somatic diseases (Firth et al., 2019; Nordentoft et al., 2013). There is consistent evidence that individuals with SMI engage in little physical activity (PA), and less than the general population (Vancampfort et al., 2017). Nyboe and Lund (2013) described the PA level of this population as hazardously low. It is therefore of interest that recent reviews show that PA has the potential to counteract several of the health risks caused by physical inactivity in this population (e.g., Firth et al., 2019; Stubbs et al., 2018). Outcomes from PA interventions have resulted in positive weight regulation, improvement of various physical health variables, as well as positive effects on mental health, illness symptoms and quality of life for various diagnoses (Dauwan, Begemann, Heringa, \& Sommer, 2016; 
Rosenbaum, Tiedemann, Sherrington, Curtis, \& Ward, 2014). Several studies have also demonstrated positive cognitive effects of PA, in particular for individuals with schizophrenia (Firth et al., 2017b). Results as to cognitive effects in relation to major depressive disorder, have so far been more equivocal (Herrman, \& Gallaghu 2018). One issue there are still no clear answers to, is the dose-response question. Therefore, it would be expected that the interest for using PA as part of psychiatric treatment is on the rise (Callaghan, 2014; WHO, 2019). However, to obtain the benefits of PA, it is necessary to be regularly physically active, something that has been reported to be challenging for individuals with SMI. Both health personnel, and individuals with SMI themselves, report motivation for PA to be a major barrier for engaging in PA as part of treatment and in life in general (Glowacki, Duncan, Gainfort, \& Faulkner, 2017; Fraser, Chapman, Brown, Whiteford, \& Burton, 2015; Happell, Platania-Phung, \& Scott, 2013). According to an extended social relational model of disability, causes for the physical inactivity may be structural or psycho-emotional (Reeve, 2004). One way of addressing the problem has been suggested by Martin (2013). Based on an overview of research from a social relational perspective on PA engagement by people with physical disabilities, Martin (2013) concluded that rehabilitation professionals need to understand behaviour change strategies and their application to people with disabilities in order to stimulate more PA. We believe that the same will apply for professionals working in psychiatric institutions.

Therefore, the overarching purposes of a collaborative project between The University J E Purkyne in the Czech Republic and the Norwegian School of Sport Sciences were: 1) To develop PA intervention programs based on current motivational theories, 2) To educate instructors and health personnel in how to implement such interventions, and 3) To evaluate the outcomes of these interventions on patients' participation in, and motivation for PA, as well as affects and health related functions. PA was defined as "a variety of movement activities designated to stimulate physical, emotional, cognitive, and social resources in the individual." This paper reports from one of the studies in the Norwegian arm of the project. Many PA intervention studies of individuals with SMI reported motivational strategies as part of their procedures. Yet, few have, in fact, systematically examined how the strategies influenced participants' motivation for PA (Farholm \& Sørensen, 2016). Consequently, more knowledge about motivation has been pointed out as an important research area within the area of PA and SMI (Vancampfort et al., 2016).

Among the few studies with a theory based motivational intervention, the mostly used motivational approaches have been motivational interview (MI) and social-cognitive theory (self-efficacy). However, none of these interventions have documented a clear improvement in the targeted motivational variables (Farholm \& Sørensen, 2016). Many intervention studies of physical activity and exercise adoption in various other populations have used Self-Determination Theory (SDT) (Ryan \& Deci, 2000). However, among 73 studies in a recent meta-analysis on SDT interventions, none of the studies included individuals with SMI (Ntoumanis et al., 2020). Even if the effects reported mostly are small to medium for most SDT constructs and health behaviour changes, there is still extensive evidence for the usefulness of SDT in understanding the motivational mechanisms of various health behaviours (Ntoumanis et al., 2020), and PA in particular (Teixeira, Carraca, Markland, Silva, \& Ryan, 2012). Cross-sectional evidence has also supported the applicability of SDT in understanding PA behaviour among individuals with SMI (Farholm, Sørensen, \& Halvari, 2016; Vancampfort, Stubbs, Venigalla, \& Probst, 2015). Ntoumanis and colleagues (2020) pointed out that more studies are needed to test "the feasibility (and efficacy) of SDT interventions in terms of disease management" and "that it is a clear gap in the existing literature identifying optimal training duration for SDT interventions in community or 
clinical settings" (Ntoumanis et al., 2020, p 25). On this background, and finding support from thoughtful works about how to translate the theory into practical guidelines (e.g., Fortier, Duda, Guerin, \& Teixeira, 2012), we decided to base the motivational PA intervention on SDT theory, and PA should be introduced and delivered according to the principles of the theory.

Further, from a scoping review of barriers and facilitators to PA among adults with depression, emotions related to PA was represented to be a major barrier for that population (Glowacki et al., 2017). Researchers in affective- reflective theory (ART) pointed to how important people's affective responses to physical activity are for future activity engagement (Brand \& Ekkekakis, 2018). The authors stressed the importance of instructors that are trained in tailoring suitable workloads as well as providing psychological support, in order to generate positive affects. To our knowledge no quantitative study has so far measured the personal experiences of affects and evaluation of own functioning related to PA of individuals with SMI, and therefore we included these aspects in this study. A PA intervention delivered according to SDT principles, supporting satisfaction of the needs for autonomy, competence and relatedness should be geared towards generation of positive affective responses to the activity, but it needs to be measured.

\section{Theoretical background}

SDT is an empirically based theory of human motivation, development, and wellness (Ryan \& Deci, 2002). The theory describes universal motivational processes for humans regardless of identity or culture (Deci \& Ryan, 2000). Earlier studies of SDT constructs within motivation for PA among individuals with psychiatric illness, seem to support that these processes are similar to individuals without such illness (Sørensen, 2006; Vancampfort et. al., 2015). Central in SDT is the distinction between different qualities of motivation. The quality of motivation is determined by the reasons why people engage in activities and can be classified into different regulations on a continuum of selfdetermination. Intrinsic regulation (doing PA because it is stimulating or enjoyable) and identified regulation (personally valuing the benefits of $\mathrm{PA}$ ) are considered to be autonomous forms of motivation regulation. Introjected regulation (doing PA to avoid feelings of guilt) and external regulation (doing PA because one is told so or to obtain tangible rewards / avoiding punishment) are considered to be controlled motivation regulation (Ryan \& Deci, 2002). Amotivation means that the person does not have any interest, intention, or motivation to engage in PA. Amotivation is a well-known phenomenon in psychiatric illness, to the extent that it is considered a symptom (Foussias \& Remington, 2010). However, one study demonstrated that PA specific motivation was associated with PA also when controlling for functioning and apathy (Farholm, Sørensen, Halvari, \& Hynnekleiv (2017). This may indicate the importance of facilitating context specific motivation (i.e., motivation for PA).

According to the theory, the autonomous forms of motivation regulation will be the most stable and robust forms, whereas the controlled forms are more driven by external pressure or avoidance (Ryan \& Deci, 2002). However, also controlled forms of motivation regulation may help initiate a behaviour, even if it is not considered desirable to keep up over time (Ryan \& Deci, 2002).

Motivation is a dynamic process and in SDT, three psychological needs are considered as the source of energy for motivation (Deci \& Ryan, 2000). The three needs are the need for autonomy (i.e., experiencing ownership of one's own actions and choices), the need for competence (i.e., succeeding with challenging tasks and be able to attain desired outcomes), and the need for relatedness (i.e., establishing a sense of mutual respect and belonging with others) (Deci \& Ryan, 2000; Ryan \& Deci, 2002). SDT acknowledges that needs satisfaction 
or needs thwarting occur in a dialectic relationship with the social environment (Deci \& Ryan, 2000). The environment of psychiatric patients is highly influenced by the institutional staff, giving them a crucial role in creating an environment that can enhance the quality of motivation for engaging in PA. Several need supportive strategies that can facilitate autonomous forms of motivation have been identified. For instance, autonomy support implies taking into account the perspective of the patients, recognising their emotions and attitudes, to promote relevant choices, and minimise external control such as reward and punishment. Providing competence support involves giving a meaningful rationale for activities, providing optimal challenges and neutral information, and positive feedback on processes. Expressing empathy, helping individuals to develop and strengthen attachments with others through PA will support the need for relatedness (Haase, Taylor, Fox, Thorp, \& Lewis, 2010). The main objectives of this study were to investigate whether there was an association between implementation of a motivational PA intervention as a part of treatment for psychiatric inpatients and: 1) change in PA level, 2) change in quality of motivation for PA, and 3) change in positive and negative affects, as well as perceived functional health.

\section{Materials and Methods}

The study reported here was carried out at a "District Psychiatric Centre" (part of a central university hospital) with 3 day/night wards housing around 30 patients. PA had been offered sporadically, but it was not an integrated part of the treatment.

\section{Research design}

The study had a longitudinal design, following inpatients over a period of two months. This study was an effectiveness study that aimed to determine whether the treatment is feasible and have measurable beneficial effects across populations and in real world-setting (Nathan, Stuart, \& Dolan, 2000). The design of such a study stands in contrast to an efficacystudy that focuses on effects of specific interventions, traditionally using a design with high internal validity with an intervention and control condition (Nathan, Stuart, \& Dolan, 2000). This study thereby contributes to the call from a recent position statement within the field, asking for a shift in research designs towards more pragmatic effectiveness trials (Stubbs et al, 2018). This is in line with the argumentation that clinical interventions should be more similar to the real treatment situation so their results might become more widely applicable (Treweek \& Zwarenstein, 2009). Most psychiatric wards in Norway tend to be small with a limited number of patients admitted. Not all patients will fit the inclusion criteria, so we could expect relatively few participants to complete the intervention. Consequently, a two phased multiple single-cases experimental design was chosen, where each participant served as his or her own control (Dallery, Cassidy, \& Raiff, 2013). It was necessary to establish a control condition with several measurements prior to the intervention. It is important to emphasise that the current design offers an examination of trends of changes in the study variables (Kazdin, 2011). The motivational physical activity intervention was implemented in addition to ordinary treatment within the psychiatric institution.

\section{Participants}

The participants were diagnosed with severe psychiatric disorders, such as schizophrenia and psychotic disorders, depressive and anxiety disorders, trauma and stressrelated disorders. The researchers collaborated with the psychiatrist in charge of treatment when deciding which patients to include in the study, following these inclusion criteria: Patients who planned to stay at the ward for minimum 8 weeks, and that were competent to give informed consent. Exclusion criteria were: Patients: less than 18 years old; disorders 
including compulsory exercise (e.g., obsessive-compulsive disorders, eating disorders), or any physical health contraindications. In order to ensure real voluntary participation, patients were able to take part in the activities without consenting to take part in the study. The patients were included in the project over a period of three months (February - April 2016). In this period, 22 patients were evaluated to fit the inclusion criteria. Twelve patients declined participation in the study, while 10 agreed to participate. A few of those who declined participation in the study sporadically participated in the activities. Two patients dropped out of the study after one and eight weeks due to: a) not finding the project suitable, and b) that the treatment ended earlier than planned. In addition, one participant attended less the $50 \%$ of the PA-sessions and was therefore excluded from the analyses. In total, this resulted in a completion rate of $32 \%$ among the eligible population.

\section{Procedures}

The baseline period lasted 10 days during which the patients took part in regular treatment, but not in PA. Baseline data collection consisted of three measuring points: the first or the second day after admission, at day five, and at day seven. Thus, the number of baseline measurements varied from three on the motivational variables and affective variables, and ten on PA (accelerometer). This was in line with current recommendations (Kazdin, 2011). Thereafter, PA was introduced twice a week, and weekly assessments were carried out each Wednesday after the PA session. The PA instructors collected activity data and were available for help while the patients answered questionnaires. Data were collected seven times during the intervention in order to get reliable data of experimental effects (Dallery et al., 2013).

\section{Training of staff and instructors}

The educational part consisted of three different waves. First, all staff were offered a 2hour lecture about the study, and the importance of both PA and motivation for PA. Second, six employees from the psychiatric ward attended an eight-hour course about various physical activities and need supportive PA instruction. These employees served as PA coinstructors during the intervention with the intention that they should take over the role as instructors after the intervention was completed. Third, a 40-hour course was given to the main PA instructors. These were Master level students in sport sciences. The content of the course was about adapting PA to a psychiatric population, about transtheoretical and SDT theories, and how to apply SDT motivational techniques at the various levels of stages of change.

\section{Motivational physical activity intervention}

During baseline, each participant had three individual talk sessions (but no PA) with a PA instructor or one of the staff, approximately 30-45 minutes for each session. These sessions gave information about the study, discussed the patients' knowledge about PA and health, expectations regarding PA, and motivation for PA. The patients' former PA experience was also discussed. They received accelerometers, equipment for physical activity, and answered questionnaires. The intervention period consisted of two weekly PA sessions $(60-75 \mathrm{~min})$ for eight weeks. The PA program was adapted to meet the participants' preferences and previous experiences with PA. Activities varied between walking, ball activities, aerobic, circuit training using different equipment (e.g., training bands, free weights, or own body weight), and playful activities and games. 


\section{Measurements}

Gender, age and diagnosis (ICD-10) were recorded as background information. In order to protect anonymity, we present only age groups and diagnoses in types, not a specific age or diagnosis.

\section{Physical activity (PA)}

The PA level of the participants was measured using a wristwatch with an accelerometer (Polar A300, Polar Electro Oy, Kempele, Finland). The wristwatch registers both steps and $3 \mathrm{D}$ acceleration, combining frequency, intensity and regularity into activation zones based on these in the activation zones "lying, sitting, low -, moderate-, and high activity. Participants were instructed to wear the wristwatch for the entire study period (not during sleep) and the data collected were steps a day, and minutes in the various activation zones. The PA instructors registered frequency of attendance in the organised PA groups and downloaded data from the Polar watches into a computer with the appropriate software (Polar Flow). Daily wear time was calculated as the sum of all five intensity zones between $06.00-24.00$ and only days with $\geq 8$ hours of wear time were included in the analysis. There is a variety of criteria for selecting the number of hours per day to reflect a valid estimation of free-living PA (Herrman, Barreira, Kang, \& Ainsworth, 2013). The 8-hour wear time criterion in the present study is at the lower end of continuum, but this cut-off was chosen to reduce the burden for participants because they were instructed to wear the watch noticeable longer ( 8 weeks) than what is typical ( 1 week) when using accelerometer to assess PA level. For the current study, two different device-based measures were chosen to reflect the PA level: number of steps and collapsing minutes of moderate and high intensity PA into the variable moderate and vigorous physical activity (MVPA).

\section{Motivation}

Motivation regulation was measured by the Behaviour Regulation in Exercise-2 (BREQ2: Markland \& Tobin, 2004). BREQ-2 is a 19-item questionnaire designed to capture reasons for physical exercise varying along a continuum of relative autonomy. The questionnaire was adapted to the native language by replacing the term "exercise" with "PA". Amotivation was measured by four items, example item: "I do not see the point in doing PA". Externally regulated motivation was measured by four items, such as "I engage in PA because other people say I should". The introjected motivation scale had three items, with example item: "I feel guilty if I do not engage in PA". These two subscales together make up the controlled motivation variable. The identified motivation scale had four items, such as "I value the benefits of PA", and the intrinsic motivation scale had four items; "I take part in PA because it is fun" as an example. These two subscales together make up the autonomous motivation variable. The 19 items were rated on a seven-point Likert-scale ranging from one (strongly disagree) to seven (strongly agree). The scale has previously been used in Norway among psychiatric outpatients with acceptable internal consistency $(\alpha=.79-.91$; Farholm et al., 2016). The items used were identical, but we included two more points on the Likert scale in order to harmonise the various scales used in the questionnaire and allow for more variation in the responses.

\section{Measures of functional health status and affects}

The Coop/WONCA questionnaire (Norwegian version: Bentsen, Natvig, \& Winnem, 1999) evaluates health and functional status. The scale assesses the patients' experiences within the last week in six domains, of which we used two, namely physical fitness and daily activities. Each item is scored on a five -point scale with one representing the best and five the worst functioning. Each score on the scale is illustrated by a pictogram to increase 
awareness and understanding of what each score means. The scale has previously shown consistent and reliable reports of acutely admitted psychiatric patients' views of their own functional capacity in Norway (Linaker \& Moe, 2005).

The affective responses of the participants were measured using the International Positive and Negative Affect Schedule Short Form (I-PANAS-SF) (Thompson, 2007). The respondents rated on a five-point Likert type scale, ranging from always to never, to what extent they had experienced, different affects (e.g., being upset, hostile, inspired, determined etc.). The questionnaire was adapted to measure how the participants had felt 'during the last week' as the original version asks how participants experience the affects in general.

\section{Data analysis}

One respondent did not answer one page of the questionnaire at one time point $\left(\mathrm{T}_{5}\right)$, resulting in missing data on quality of motivation (BREQ-2). Single item missing occurred less than $5 \%$ (22 occasions). Results from Little's MCAR test using IBM SPSS 24.0 indicated that the data were missing completely at random $\left(\chi_{2}=80.272, \mathrm{df}=96, \mathrm{p}=0.876\right)$. To obtain a complete dataset, an estimation of mean on each variable for each individual with a missing item was calculated and imputed.

Simulation Modelling Analysis for time-series was conducted. That is a statistical analysis using bootstrapping procedures to determine empirical significance level (Borckardt et al., 2008). This approach resamples from known distributions to determine exact probabilities instead of probability estimates. The analysis corrects for autocorrelation within each variable in the results. The analysis explores for partial correlation between the dependent variable and the phase vector, and the results indicate whether the data is increasing or decreasing systematically from the baseline phase to the intervention phase on the dependent variable for each participant (Borckardt et al., 2008). Results are reported by a mean value for both baseline and intervention phase, and the magnitude in changes is reported and interpreted in strength by Spearman's Rho (negligible (o - .20), weak (0.21 0.40), moderate (0.41-0.60), strong (0.61-0.80), or very strong (0.81-1.00) (Prion \& Haerling, 2014). Spearman's Rhos were evaluated to indicate meaningful changes if they were moderate, strong and very strong. Spearman's Rhos were evaluated to indicate no change if they were negligible or weak.

Based on the Simulation Modelling Analysis results, individual profiles were created for each participant on the study variables in order to explore trend of effects of participating in the intervention. The individual profiles were determined to be either: Favourable development ( $=$ increase in scores on PA and autonomous motivation regulation; decrease in controlled motivation regulation and amotivation); Unfavourable development (= the opposite change in scores compared to the favourable development); Mixed development (= a mixture of favourable and unfavourable development in the scores); Unchanged (= no change in scores).

\section{Ethics}

The ethical aspects are particularly important when studying vulnerable groups. Therefore, an internal code of ethics was developed and integrated in the project. The study received approval by the Regional Ethics Committee of South-East Norway (2015/1536). Prior to the intervention, the responsible therapist evaluated the participants' competence to give informed consent. Then, the participants received information about the project and signed an informed consent form in accordance with the Declaration of Helsinki. Being inpatients, they had access to therapists should any adverse effects of the participation occur. Identifiable data was stored on data servers provided by each involved institution. 
Anonymised data were stored on computers not connected to internet and locked in safes when not used.

\section{Results}

\section{Participants}

Seven participants ( 3 females, 4 males) completed the intervention. Table 1 displays data describing demographics, types of diagnoses and attendance rate for the motivational PA intervention. There was an expected variation in age, gender, and diagnoses. We identify the participants by fictional first names and use age groups and rough types of diagnoses to protect anonymity.

Table 1. Demographics for participants and attendance rate in the PA intervention.

\begin{tabular}{llll}
\hline Name & Age-span & Type of diagnosis & Attendance rate PA intervention \\
\hline Anna & $40-44$ & Anxiety & $13 / 14$ \\
Emma & $35-39$ & Affective Bipolar & $8 / 14$ \\
James & $20-24$ & Affective & $11 / 14$ \\
Lucy & $20-24$ & Affective & $10 / 14$ \\
Mark & $25-29$ & Psychosis & $13 / 14$ \\
Tom & $40-44$ & Affective Bipolar & $8 / 14$ \\
Will & $25-29$ & Anxiety & $7 / 14$ \\
\hline
\end{tabular}

Primary analyses

For PA (see Table 2), the individual profiles showed favourable development for four participants (Anna, Emma, Mark, \& Will), one had an unchanged profile (James), and two had an unfavourable development (Lucy \& Tom).

Table 2. Simulation Modelling Analyses results for the physical activity (PA) at baseline (B) and intervention (I).

\begin{tabular}{lllllllll}
\hline Name & Variable & M $(\mathbf{B})$ & SD & M (I) & SD & RHO & Profile \\
\hline Anna & PA & Steps & 6456.10 & 1661.4 & 7575.4 & 1337.5 & $+.41 \mathrm{~F}+$ & Favourable \\
& & MVPA & 42.00 & 18.88 & 47.71 & 10.21 & +.21 & \\
\hline \multirow{2}{*}{ Emma } & PA & Steps & 3120.80 & 2279.4 & 5904.1 & 1745.6 & $+.62 \mathrm{~F}++$ & Favourable \\
& & MVPA & 19.50 & 21.78 & 47.57 & 17.3 & $+.62 \mathrm{~F}++$ & \\
\hline \multirow{2}{*}{ James } & PA & Steps & 6632.10 & 1831.0 & 6818.9 & 1793.9 & .000 & Unchanged \\
& & MVPA & 35.50 & 12.2 & 41.86 & 12.2 & +.10 & \\
\hline Lucy & PA & Steps & 10406.8 & 1379.9 & 8186.5 & 2620.0 & $-.41 \mathrm{U}+$ & Unfavourable \\
& & MVPA & 62.00 & 15.0 & 46.43 & 18.8 & $-.41 \mathrm{U}+$ & \\
\hline \multirow{2}{*}{ Mark } & PA & Steps & 7438.8 & 1242.9 & 8216.2 & 1236.3 & $+.25 \mathrm{~F}+$ & Favourable \\
& & MVPA & 35.50 & .95 & 42.2 & 5.2 & $+.51 \mathrm{~F}+$ & \\
\hline \multirow{2}{*}{ Tom } & PA & Steps & 15045.30 & 1615.5 & $12321 .-$ & 4088.3 & $-.41 \mathrm{U}+$ & Unfavourable \\
& & MVPA & 95.50 & 19.1 & 85.71 & 33,5 & -.21 & \\
\hline Will & PA & Steps & 6133.8 & 1409.6 & 6794.8 & 2272.3 & +.25 & Favourable \\
& & MVPA & 19.50 & 3.18 & 36.43 & 15.4 & $+.52 \mathrm{~F}++$ & \\
\hline
\end{tabular}

Note: PA = Physical Activity; MVPA = Moderate and vigorous PA, M (B) = Mean Baseline; M (I) = Mean Intervention; F = Favourable change; U = Unfavourable change; Strength Spearman's Rho: $+=.41-.60$ (Moderate); $++=.61-.80$ (Strong); $+++.81-1.00$ (Very strong).

From the motivation profiles (Table 3) there was a favourable development for three participants (Anna, Lucy \& Mark), mixed development for two (James, Tom), one had an unfavourable development (Emma), and one showed no change (Will).

For the positive and negative affect (Table 4), five of the participants had a favourable development (Anna, Emma, James, Lucy, and Mark). Tom had an unfavourable development in affect. Will demonstrated no change. For the functional status, six participants had a favourable development, only Will demonstrated no change. 
Table 3. Simulation Modelling Analyses results for the quality of motivation (QM) at baseline and intervention.

\begin{tabular}{|c|c|c|c|c|c|c|c|c|}
\hline Name & Vari & able & M (B) & SD & M (I) & SD & RHO & Profile \\
\hline \multirow[t]{3}{*}{ Anna } & QM & Autonomous & 5.84 & .26 & 6.02 & .17 & $+.43 \mathrm{~F}+$ & \\
\hline & & Controlled & 3.62 & .42 & 3.84 & .28 & .35 & Favourable \\
\hline & & Amotivation & 1.00 & .00 & 1.00 & .00 & - & \\
\hline \multirow[t]{3}{*}{ Emma } & QM & Autonomous & 2.50 & .66 & 2.95 & .50 & +.31 & \\
\hline & & Controlled & 3.00 & .86 & 3.90 & .44 & $+.58 \mathrm{U}+$ & Unfavourable \\
\hline & & Amotivation & 4.50 & 1.30 & 3.45 & .47 & -.35 & \\
\hline \multirow[t]{3}{*}{ James } & QM & Autonomous & 4.77 & .23 & 3.89 & .99 & $-.57 \mathrm{U}++$ & \\
\hline & & Controlled & 2,63 & .74 & 1.6 & .68 & $-.62 \mathrm{~F}++$ & Mixed \\
\hline & & Amotivation & 3.17 & .52 & 2.50 & .92 & $-.46 \mathrm{~F}+$ & \\
\hline \multirow[t]{3}{*}{ Lucy } & $\mathrm{QM}$ & Autonomous & 5.38 & .13 & 5.59 & .23 & $+.47 \mathrm{~F}+$ & \\
\hline & & Controlled & 2.57 & .00 & 1.96 & .22 & $-.81 \mathrm{~F}+++$ & Favourable \\
\hline & & Amotivation & 1.00 & .00 & 1.00 & .00 & - & \\
\hline \multirow[t]{3}{*}{ Mark } & QM & Autonomous & 4.42 & .44 & 5.00 & .37 & $+.58 \mathrm{~F}+$ & \\
\hline & & Controlled & 2.57 & .43 & 2.7 & .24 & +.19 & Favourable \\
\hline & & Amotivation & 1.42 & .72 & 1.4 & .54 & .000 & \\
\hline \multirow[t]{3}{*}{ Tom } & QM & Autonomous & 5.96 & .40 & 6.46 & .44 & $+.46 \mathrm{~F}+$ & \\
\hline & & Controlled & 2.48 & .21 & 3.00 & .39 & $+.65 \mathrm{U}++$ & Mixed \\
\hline & & Amotivation & 1.00 & .00 & 1.00 & .00 & - & \\
\hline \multirow[t]{3}{*}{ Will } & $\mathrm{QM}$ & Autonomous & 6.34 & .61 & 6.11 & .57 & -.27 & \\
\hline & & Controlled & 3.33 & 1.21 & 3.63 & .27 & +.33 & Unchanged \\
\hline & & Amotivation & 1.00 & .00 & 1.00 & .00 & - & \\
\hline
\end{tabular}

Note: $\mathrm{QM}=$ Quality of motivation; $\mathrm{M}(\mathrm{B})=$ Mean Baseline; $\mathrm{M}(\mathrm{I})=$ Mean Intervention; $\mathrm{F}=$ Favourable change; $\mathrm{U}=$ Unfavourable change; Strength Spearman's Rho: $+=.41-.60$ (Moderate); $++=.61-.80$ (Strong); +++.81 -1.00 (Very strong).

There was no clear trend for favourable or unfavourable individual profiles when all the outcome variables were combined. However, we could distinguish some predominantly positive profiles (Anna, Emma, Lucy, and Mark), some more mixed (James, and Tom), and one with little change (Will, who also had the lowest participation rate). It is noteworthy that all participants experienced a favourable development in at least one variable, and that those with the highest participation rate demonstrated the most positive profiles.

Other findings of interest were that the PA data indicated that all participants were in moderate-to-vigorous PA (MVPA) more than 30 minutes per day on average during the intervention. Five participants had clearly favourable motivational profiles during the intervention phase (high scores on autonomous regulation and low scores on controlled regulation and amotivation). One participant (James) scored relatively high on autonomous regulation and low-to-moderate on controlled regulation and amotivation. Another participant (Lucy) had moderate scores on all regulations. 
Table 4. Simulation Modelling Analyses results for Functional status* at baseline and intervention.

\begin{tabular}{|c|c|c|c|c|c|c|c|c|}
\hline Name & Variable & & M (B) & SD & $\mathbf{M}(\mathbf{I})$ & SD & RHO & Profile \\
\hline \multirow[t]{4}{*}{ Anna } & \multirow[t]{2}{*}{ Affect } & Positive & 2.80 & .20 & 3.42 . & .34 & $+.69^{\mathrm{F}++}$ & Favourable \\
\hline & & Negative & 3.08 & .14 & 3.36 & .40 & +.39 & \\
\hline & \multirow{2}{*}{$\begin{array}{l}\text { Functional } \\
\text { status* }\end{array}$} & Physical Shape & 1.00 & .00 & 1.14 & .38 & +.22 & Favourable \\
\hline & & Daily activity & 3.33 & .58 & 3.00 & .00 & $-.51^{\mathrm{F}+}$ & \\
\hline \multirow[t]{4}{*}{ Emma } & \multirow{2}{*}{ Affect } & Positive & 2.22 & .03 & 2.34 & .38 & -.12 & Favourable \\
\hline & & Negative & 4.17 & .14 & 3.32 & .47 & $-.81^{\mathrm{F}+++}$ & \\
\hline & \multirow{2}{*}{$\begin{array}{l}\text { Functional } \\
\text { status* }\end{array}$} & Physical Shape & 3.33 & .38 & 2.57 & .53 & $-.57^{\mathrm{F}+}$ & Favourable \\
\hline & & Daily Activity & 4.00 & 1.00 & 3.43 & .53 & -.34 & \\
\hline \multirow[t]{4}{*}{ James } & \multirow[t]{2}{*}{ Affect } & Positive A & 1.73 & .50 & 2.73 & .68 & $+.78^{\mathrm{F}++}$ & Favourable \\
\hline & & Negative A & 2.75 & .43 & 2.04 & .70 & $-.51^{\mathrm{F}+}$ & \\
\hline & \multirow{2}{*}{$\begin{array}{l}\text { Functional } \\
\text { status* }\end{array}$} & Physical Shape & 2.00 & 1.00 & 1.00 & .00 & $-.75^{\mathrm{F}++}$ & Favourable \\
\hline & & Daily Activity & 3.33 & 1.15 & 1.67 & .82 & $-.66^{\mathrm{F++}}$ & \\
\hline \multirow[t]{4}{*}{ Lucy } & \multirow[t]{2}{*}{ Affect } & Positive & 3.13 & .42 & 3.60 & .38 & $+.54^{\mathrm{F}+}$ & Favourable \\
\hline & & Negative & 4.25 & .43 & 4.32 & .45 & +.08 & \\
\hline & \multirow{2}{*}{$\begin{array}{l}\text { Functional } \\
\text { status* }\end{array}$} & Physical Shape & 1.33 & .58 & 1.00 & .00 & $-.51^{\mathrm{F}+}$ & Favourable \\
\hline & & Daily Activity & 2.00 & .00 & 1.14 & .38 & $-.80^{\mathrm{F}+++}$ & \\
\hline \multirow[t]{4}{*}{ Mark } & \multirow[t]{2}{*}{ Affect } & Positive & 2.93 & .31 & 3.57 & .18 & $+.81^{\mathrm{F}+++}$ & Favourable \\
\hline & & Negative & 3.83 & .29 & 3.96 & .09 & +.27 & \\
\hline & \multirow{2}{*}{$\begin{array}{l}\text { Functional } \\
\text { status* }\end{array}$} & Physical Shape & 3.00 & .00 & 1.57 & .98 & $+.18^{\mathrm{F}++}$ & Favourable \\
\hline & & Daily Activity & 4.00 & .00 & 4.00 & .00 & - & \\
\hline \multirow[t]{4}{*}{ Tom } & \multirow[t]{2}{*}{ Affect } & Positive & 3.67 & .42 & 3.43 & .66 & -.19 & Unfavourable \\
\hline & & Negative & 2.17 & .14 & 2.75 & .35 & $+.75^{\mathrm{U}++}$ & \\
\hline & \multirow{2}{*}{$\begin{array}{l}\text { Functional } \\
\text { status* }\end{array}$} & Physical Shape & 3.00 & 1.41 & 1.50 & .55 & $-.62^{\mathrm{F}++}$ & Favourable \\
\hline & & Daily Activity & 4.00 & .00 & 3.50 & .84 & -.33 & \\
\hline \multirow[t]{4}{*}{ Will } & \multirow[t]{2}{*}{ Affect } & Positive & 3.13 & .61 & 2.77 & .29 & -.33 & Unchanged \\
\hline & & Negative & 2.41 & .14 & 2.64 & .56 & +.20 & \\
\hline & \multirow{2}{*}{$\begin{array}{l}\text { Functional } \\
\text { status* }\end{array}$} & Physical Shape & 2.00 & 1.00 & 2.43 & .79 & +.25 & Unchanged \\
\hline & & Daily Activity & 3.00 & 1.00 & 3.14 & .90 & +.08 & \\
\hline
\end{tabular}

Note: Functional status = Coop/Wonca subscales Physical Shape \& Daily activity. ${ }^{* N B}$ ! Low scores = positive; $\mathrm{M}(\mathrm{B})=$ Mean Baseline; $\mathrm{M}(\mathrm{I})$ = Mean Intervention; F = Favourable change; $\mathrm{U}=$ Unfavourable change; Strength Spearman's Rho: $+=.41-.60$ (Moderate); $++=.61-.80$ (Strong); $+++.81-1.00$ (Very strong).

\section{Discussion}

This study was a two-phase single cases experimental design. The intervention took place in an institution that had no systematic PA program from before. The motivational physical activity intervention was feasible, but only about $32 \%$ of the eligible patients completed the intervention. This demonstrates some of the dilemmas in psychiatric institutions in Norway these days, with attempts to keep hospitalisation periods as short as possible (Pedersen \& Kolstad, 2009). The result is often difficulties as to what to give priority during the stay for individuals with a complex life situation (Sørensen, Bentzen, \& Farholm, 2019). It is also a demonstration of the motivational situation among both staff and some patients formerly described (Glowacki et al., 2017; Happell et al., 2013). However, all the patients who participated, engaged in moderate-to-vigorous physical activity 30 minutes per day. The results for development in motivation and PA were equivocal. There were individual differences in development as to both PA and quality of motivation. These variations showed no systematic relationship with diagnose type, indicating that the individual history and experience with physical activity is of greater importance. However, those who participated most frequently in the PA program demonstrated more favourable development of motivation. 
The relatively high PA engagement must be seen in light of the fact that only $32 \%$ of the eligible patients accepted and completed the motivational physical activity intervention. Recruitment to exercise programs in residential care has been reported to be challenging. Firth et. al., (2017a) recruited only $27.5 \%$ of the population of 4 residential care services to a 10-week exercise program, and 35\% of those dropped put in the course of the study.

As mentioned, the reasons for this may be complex. However, these results also show that if individuals with SMI are offered an adapted PA program, they can engage in about the same amount of PA as the general population, such that $31 \%$ of the adult Norwegian population engage in at least $150 \mathrm{~min} /$ week of moderate or vigorous PA (Hansen, Kolle, \& Anderssen, 2014). The two participants that reduced their PA level during the intervention were the two participants who were the most physically active during baseline. An explanation could be that during a hospital stay it may be difficult to keep up a high PA level over time, even when taking part in a PA intervention.

We should also take into consideration that all participants, but one, had higher scores on the autonomous motivational regulations than on the controlled regulations both at baseline and during the intervention. This probably again reflects the selection of motivated patients through voluntary participation. The fact that participation has to be voluntary will result in a natural selection of motivated patients. Even if these results are based on a small number of participants, we do think that that this individual approach demonstrates the health promotion nature of what PA has to offer for individuals with mental illness as part of therapy. This illustrates that their previous experiences may influence their responses to the motivational PA intervention, as suggested by Brand \& Ekkakakis in the ART theory (2018). A closer examination of the individual profiles supports this idea. Tom, for instance, was highly active at baseline and he scored high on autonomous rather than controlled motivation. During the hospitalisation, the data show that Tom was not able to maintain his high PA level. Both his autonomous and controlled motivation increased indicating that Tom may have felt that he should be able to maintain his high PA level. Another example is Emma. She was the least active participant at baseline and displayed low levels of all motivational regulations and relatively high level of amotivation. During the intervention, her amotivation decreased and all other regulations increased, but with the highest increase in external regulations. Such a development may indicate that Emma had little intention to engage in PA at baseline, but that the motivational PA intervention mainly influenced her controlled motivation regulation to do PA. In order to get individuals started with PA, increasing controlled motivation can often be a viable starting point, and may later be used to facilitate more autonomous motivation for long-term engagement in PA (Gillison, Osborn, Standage, \& Skevington, 2009; Thøgersen-Ntoumani \& Ntoumanis, 2006).

What we can see clearly in the individual-centred approach is that the patients differ in experience and PA background and it is likely they respond differently to the intervention program or the activity program in itself. The individual responses towards the motivational PA intervention are also reflected in the lack of systematic associations between development in PA and development in motivation for PA. At a group level such individual differences, that are not related to diagnosis, age, or gender, will make positive and negative effects outweighing each other. An individual-centred approach may therefore be better than a group based randomised control trial (RCT) in order to learn more about the antecedents of positive development. It may also be more in line with a social relational model of disability (Thomas, 2004). It also raises the question: What is a successful intervention? Does it have to be successful for all participants on all variables studied? How could positive trends in the results have been strengthened? In a review of studies on the effect of exercise on major depression, Schuch et al., (2016) identified 11 individual and composite factors that 
could moderate the therapeutic effect of PA, and demonstrated the complexity of these relations.

The small, positive trends in development of motivation therefore raise the question if the intervention was too short, or if the education of personnel was not extensive enough. Would more time and extensive education develop these trends further? Among the few other projects to compare with is the intervention by Beebe et al. (2010) who based an intervention on self-efficacy theory. The main aim of the intervention was to increase the motivation for PA in a population with SMI. There was a modest increase in self-efficacy, but no significant group $\mathrm{x}$ time interaction effect for neither self-efficacy nor outcome expectations. Another project based in self-efficacy theory (Göhner, Dietsche, \& Fuchs, 2015), reported that a motivational program in addition to an existing sport program was successful for SMI patients who were initially minimally active. However, at a 6 month follow up, the differences between the intervention group and the control group had levelled out.

It is apparent that more knowledge about interventions to influence motivation for PA is needed. In the study reported here, it is however also likely that motivation was affected before the start of the intervention, either by the information about and the attention around the study, or also by receiving the accelerometer during baseline. Research has demonstrated facilitative effects of events or actions on subsequent associated responses, often called a priming effect (Molden, 2014), which may have taken place.

It is further debatable what should be characterised as a favourable and unfavourable development of motivation. We initially defined this strictly according to the theory, which is that an increase in controlled motivation is not positive. However, we will argue that an increase in controlled motivation is not always unfavourable. With a very low PA level and little PA experience initially, it may be a good start that the extrinsic motivation increases (Gillison et al., 2009; Thøgersen-Ntoumani \& Ntoumanis, 2006).

\section{Limitations}

The motivational PA intervention was implemented in addition to ordinary treatment within the psychiatric institution. The current research therefore acknowledges the challenges in drawing conclusions of causality as a result primarily from the intervention (Kline, 2011). On the other hand, this is closer to a realistic situation for the patients than a PA only intervention, so the external validity is higher. However, the power of these findings would have been stronger with more measurement points both during the baseline period and during the intervention (Dallery et al., 2013; Kazdin, 2011), but this was difficult to obtain in the time available.

Even device-based measures of PA have limitations; accelerometers underreport some types of activity because they do not measure resistance, e.g., intensity of strength exercises. In addition, the participants received the accelerometers at the beginning of the baseline period, and there are good reasons to believe that this influenced both the PA and the motivation for PA with some of the participants (Dencker \& Andersen, 2011).

Self-reported measures may in some situations be less trustworthy, such as recalling experience of various affects or functional status during the last week. Also, in line with our belief that experiences and responses to complex behaviours such as PA are determined by other factors than psychiatric diagnoses and medication, the lack of impact of those may be considered a limitation. Finally, in the kind of intervention described here, participation has to be voluntary for both ethical and practical purposes, so there will be a skewed selection of participants. 


\section{Conclusions}

A motivational PA intervention was feasible as part of psychiatric treatment and resulted in an overall small, positive development in motivation, affects and measures of functional status. The results were more mixed as to an increase in PA, but the participants had very different starting points. The individual differences in the results highlight that individualising the PA program at the ward should be a key element when offering PA as part of treatment to individuals with SMI. The individual differences also demonstrate the importance of using research methods that can reveal such individual differences in response to PA so that researchers can learn more about the antecedents of PA participation among this population.

\section{Perspectives}

This article should be of relevance for the APA field because it deepens our understanding of the complexity of both the life situation and PA history of the individual participant, and of the phenomenon of PA. Such complexity may in turn affect the therapeutic effects of an activity program. However, the results show that the quality of the motivation for PA of the individual participant may be improved. Stimulating the motivation for PA should therefore be an important task for health personnel Further, in practice, APA is very often delivered in small groups, and these results demonstrate the importance of using research methodology that allows the study of small groups, and where individual differences are displayed rather than hidden in group means. The European APA literature base is also in need for more studies and knowledge in the field of mental health. Such knowledge is needed both in order to broaden the scope of APA, but also because mental health problems seem to be increasing especially among younger people, making APA even more relevant.

\section{Author affiliations:}

$1 \quad$ Institute of Sport and Social Science of Coaching and Psychology, Norwegian School of Sport Sciences marit.sorensen@nih.no

$2 \quad$ Department of Teacher Education and Outdoor Studies, Norwegian School of Sport Sciences marte.bentzen@nih.no

3 The University College of Østfold, anders.farholm@hiof.no

* $\quad$ Correspondence: marit.sorensen@nih.no

Author Contributions: PI of the Norwegian arm of the project: MS.; Conceptualization, M.S. \& M.B.; Methodology, M.S. \& M.B.; Formal Analysis, M.B..; Writing-Original Draft Preparation, M.S. \& A.F.; WritingReview \& Editing, M.S., M.B. \& A.F.

Funding: This research was funded with the kind support of Norway Grants, Czech-Norwegian Research Program (CZo9), grant number [7F14500.].

Acknowledgments: : We would like to thank the participants and the staff in the psychiatric center for their efforts and enthusiasm during the project. We would also like to thank our Czech colleagues for their efforts in applying for the grant and positive collaboration in making the total project a reality.

Conflicts of Interest: The authors declare no conflict of interest

\section{References}

Beebe, L. H., Smith, K., Burk, R., Dessieux, O., Velligan, D., Tavakoli, A., \& Tennison, C. (2010). Effect of a motivational group intervention upon exercise self-efficacy and outcome expectations for exercise in Schizophrenia Spectrum Disorders. Journal of the Psychiatric Nurses Association, 16, 105-13. https://doi.org/10.1177/1078390310364428

Bentsen, B.G., Natvig, B., \& Winnem, M. (1999). Questions you didn’t ask? COOP/WONCA Charts in clinical work and research. World Organization of Colleges, Academies and Academic Associations of General Practitioners/Family Physicists. Family Practice, 16, 190- 195. https://doi.org/10.1093/fampra/16.2.190 
Biswas, A., Oh, P. I., Faulkner, G. E., Bajaj, R. R., Silver, M. A., Mitchell, M. S., \& Alter, D. (2015). Sedentary time and its association with risk for disease incidence, mortality, and hospitalization in adults: a systematic review and meta-analysis. Annals of Internal Medicine, 162, 123-132. https://doi.org/10.7326/M14-1651

Borckardt, J. J., Nash, M. R., Murphy, M. D., Moore, M., Shaw, D., \& O’Neil, P. (2008). Clinical practice as a natural laboratory for psychotherapy research: A guide to casebased time-series analysis. American Psychologist, 63, 77-95. https://doi.org/10.1037/0003-066X.63.2.77

Brand, R., \& Ekkekakis, P. (2018). Affective-reflective theory of physical inactivity and exercise: foundations and preliminary evidence. German Journal of Exercise and Sport Research, 48, 48-58. https://doi.org/10.1007/s12662-017-0477-9

Callaghan, P. (2004). Exercise: a neglected intervention in mental health care? Journal of Psychiatric \& Mental Health Nursing, 11, 476-483. https://doi.org/10.1111/j.13652850.2004.00751.x

Dallery, J., Cassidy, R. N., \& Raiff, B. R. (2013). Single-case experimental designs to evaluate novel technology-based health interventions. Journal of Medical Internet Research, 15(2) e22. https://doi.org/10.2196/jmir.2227

Dauwan, M., Begemann, M. J., Heringa, S. M., \& Sommer, I. E. (2016). Exercise improves clinical symptoms, quality of life, global functioning, and depression in schizophrenia: A systematic review and meta-analysis. Schizophrenia Bulletin, 42, 588-599. https://doi.org/10.1093/schbul/sbv164

Deci, E. L., \& Ryan, R. M. (2000). The "what" and "why" of goal pursuits: Human needs and the self-determination of behavior. Psychological Inquiry, 11, 227-268. https://doi.org/10.1207/S15327965PLI1104 01

Dencker, M., \& Andersen, L. B. (2011). Accelerometer-measured daily physical activity related to aerobic fitness in children and adolescents. Journal of Sports Sciences, 29, 887-895. https://doi.org/10.1080/02640414.2011.578148

Farholm, A., \& Sørensen, M. (2016). Motivation for physical activity and exercise in severe mental illness: A systematic review of intervention studies. International Journal of Mental Health Nursing, 25, 194-205. https://doi.org/10.1111/inm.12214

Farholm, A., Sørensen, M., \& Halvari, H. (2016). Motivational factors associated with physical activity and quality of life in people with severe mental illness. Scandinavian Journal of Caring Sciences, 31(4), 914-921. https://doi.org/10.1111/scs.12413

Farholm, A., Sørensen, M., Halvari, H. \& Hynnekleiv, T. (2017). Associations between physical activity and motivation, competence, functioning, and apathy in inhabitants with mental illness from a rural municipality: a cross-sectional study. BMC Psychiatry, 17(1), 1-11. https://doi.org/10.1186/s12888-017-1528-3

Firth, J., Carney, R., Pownall, M., French, P., Elliott, R.,Cotter, J., \& Yung, A.R. (2017a). Challenges in implementing an exercise intervention within residential care services. A mixed-method study. Mental Health and Physical Activity,12, 141-146. https://doi.org/10.1016/j.mhpa.2017.04.004 1755-2966

Firth, J., Siddiqi, N., Koyanagi, A., Siskind, D. J., Rosenbaum, S., Galletly, C., ... Stubbs, B. (2019). The Lancet Psychiatry Commission : a blueprint for protecting physical health in people with mental illness. The Lancet Psychiatry, 6(8), 675-712. https://doi.org/10.1016/S2215-0366(19)30132-4

Firth, J., Stubbs, B., Rosenbaum, S., Vancampfort, D., Malchow, B., Schuch, F...... Yung, A.R. (2017b). Aerobic exercise improves cognitive function in people with schizophrenia: A systematic review and meta-analysis. Scizhophrenia Bulletin, 43, 546 - 556. https://doi.org/10.1093/schbul/sbw115

Fortier, M.S., Duda, J. L., Guerin, E., \& Teixeira, P. J. (2012). Promoting physical activity: development and testing of self-determination theory-based interventions.

International Journal of Behavioral Nutrition and Physical Activity, 9(1), 1-14. https://doi.org/10.1186/1479-5868-9-20

Foussias, G., \& Remington, G. (2010). Negative symptoms in schizophrenia: Avolition and Occams's razor. Schizophrenia Bulletin, 36, 359-369.

https://doi.org/10.1093/schbul/sbno94 
Fraser, S. J., Chapman, J. J., Brown, W. J., Whiteford, H. A., \& Burton, N. W. (2015). Physical activity attitudes and preferences among inpatient adults with mental illness. International Journal of Mental Health Nursing, 24, 413-420. https://doi.org/10.1111/inm.12158

Gillison, F., Osborn, M., Standage, M., \& Skevington, S. (2009). Exploring the experience of introjected regulation for exercise across gender in adolescence. Psychology of Sport and Exercise, $10(3), 309-319$. https://doi.org/10.1016/j.psychsport.2008.10.004

Glowacki, K., Duncan, M. J., Gainfort, H. \& Faulkner, G. (2017). Barriers and facilitators to physical activity and exercise among adults with depression: A scoping review. Mental Health and Physical Activity, 13, 108 -119. https://doi.org/ 10.1016/j.mhpa.2017.10.001

Göhner, W., Dietsche, C., \& Fuchs, R. (2015). Increasing physical activity in patients with mental illness. A randomized controlled trial. Patient Education and Counselling, 98, 1385-1392. https://doi.org/10.1016/j.pec.2015.06.006

Haase, A. M., Taylor, A. H., Fox, K. R., Thorp, H., \& Lewis, G. (2010). Rationale and development of the physical activity counselling intervention for a pragmatic Trial of Exercise and Depression in the UK (TREAD-UK). Mental Health and Physical Activity, 3, 85-91. https://doi.org/10.1016/j.mhpa.2010.09.004

Hansen, B. H., Kolle, E., \& Anderssen, S. A. (2014). Fysisk aktivitetsnivå blant voksne og eldre i Norge: Oppdaterte analyser basert på nye nasjonale anbefalinger $i 2014$. [Physical activity level among adults in Norway: Updated analyses based on the new national guidelines from 2014]. Oslo: Norwegian Directorate of Health.

Happell, B., Platania-Phung, C., \& Scott, D. (2013). Survey of Australian mental health nurses on physical activity promotion. International Journal of Mental Health Promotion, 15, 148-161. https://doi.org/10.1111/jpm.12041

Herrmann, S. D., Barreira, T. V., Kang, M., \& Ainsworth, B. E. (2013). How many hours are enough? Accelerometer wear time may provide bias in daily activity estimates. Journal of Physical Activity and Health, 10, 742-749. https://doi.org/10.1123/jpah.10.5.742

Kazdin, A. E. (2011). Single-case research designs: Methods for clinical and applied settings. Oxford: Oxford University Press.

Kline, R. B. (2011). Principles and practice of structural equation modeling (3rd ed.). New York, NY: The Guildford Press.

Linaker, O. M., \& Moe, A. (2005). The COOP/WONCA charts in an acute psychiatric ward. Validity and reliability of patients' self-report of functioning. Nordic Journal of Psychiatry, 59, 121-6. https://doi.org/10.1080/08039480510022918

Kolstad, A., \& Pedersen, P. (2009). De-institutionalisation and trans-institutionalisation changing trends of inpatient care in Norwegian mental health institutions 1950-2007. International Journal of Mental Health Systems, 3(1), 28. https://doi.org/10.1186/1752-4458-3-28

Markland, D., \& Tobin, V. (2004). A modification to the behavioural regulation in exercise questionnaire to include an assessment of amotivation. Journal of Sport \& Exercise Psychology, 26, 191-196. https://doi.org/10.1123/jsep.26.2.191

Martin, J. (2013). Benefits and barriers to physical activity for individuals with disabilities: a social-relational model of disability perspective. Disability and Rehabilitation, 35(24), 2030-2037. https://doi.org/10.3109/09638288.2013.802377

Molden, D. C. (2014). Understanding priming effects in social psychology: What is "social priming" and how does it occur? Social Cognition, 32, Special issue, 1-11. https://doi.org/10.1521/soco.2014.32.supp.243

Nathan, P. E., Stuart, S. P., \& Dolan, S. L. (2000). Research on psychotherapy efficacy and effectiveness: Between scylla and charybdis? Psychological Bulletin, 126, 964-981. https://doi.org/10.1037/0033-2909.126.6.964

Nordentoft, M., Wahlbeck, K., Hallgren, J., Westman, J., Osby, U., Alinaghizadeh, H., ... Laursen, T. M. (2013). Excess mortality, causes of death and life expectancy in 270,770 patients with recent onset of mental disorders in Denmark, Finland and Sweden. PLoS One, 8, e55176. https://doi.org/10.1371/journal.pone.0055176

Ntoumanis, N., Ng, J.Y.Y, Prestwich, A., Quested, E., Hancox, J.E., Thøgersen-Ntoumani, C., .... Williams, G. C. (2020): A meta-analysis of self-determination theory-informed intervention studies in the health domain: effects on motivation, health behavior, 
physical, and psychological health. Health Psychology Review, 1-31.

https://doi.org./10.1080/17437199.2020.1718529

Nyboe, L., \& Lund, H. (2013). Low levels of physical activity in patients with severe mental illness. Nordic Journal of Psychiatry, 67, 43-46.

https://doi.org/10.3109/08039488.2012.675588

Prion, S., \& Haerling, K. A. (2014). Making sense of methods and measurement: Spearman-Rho ranked-order correlation coefficient. Clinical Simulation in Nursing, 1O, 535-536. https://doi.org/10.1016/j.ecns.2014.07.005

Reeve, D. (2004). Psycho-emotional dimensions of disability and the social model. In C. Barnes, \& G. Mercer (Eds.) Implementing the Social Model of Disability: Theory and Research. Leeds: The Disability Press, pp. 83-100.

Rosenbaum, S., Tiedemann, A., Sherrington, C., Curtis, J., \& Ward, P. B. (2014). Physical activity interventions for people with mental illness: A systematic review and metaanalysis. Journal of Clinical Psychiatry, 75, 964-974. https://doi.org/10.4088/JCP.13ro8765

Ryan, R. M., \& Deci, E. L. (2002). An overview of self-determination theory: an organisimic-dialectical perspective. In E.L. Deci \& R. M. Ryan (Eds.), Handbook of selfdetermination research (pp. 3-33). Rochester, NY: The University of Rochester Press.

Schuch, F. B., Dunn, A. L., Kanitz, A. C., Delevatti, R. S., \& Fleck, M. P. ( 2016). Moderators of response in exercise treatment for depression: A systematic review. Journal of Affective Disorders, 195, 40-49. https://doi.org/10.1016/j.jad.2016.01.014

Stubbs, B., Vancampfort, D., Hallgren, M., Firth, J., Veronese, N., Solmi......... Kahl, K. G. (2018). EPA guidance on physical activity as a treatment for severe mental illness: a meta-review of the evidence and Position Statement from the European Psychiatric Association (EPA), supported by the International Organization of Physical Therapists in Mental Health (IOPTMH). European Psychiatry, 54, 124-144. https://doi.org/10.1016/j.eurpsy.2018.07.004

Sun M., Lanctot K., Herrmann N., \& Gallagher D. (2018). Exercise for cognitive symptoms in depression: A systematic review of interventional studies. Canadian Journal of Psychiatry, 63(2), 115-128. https://doi.org/10.1177/0706743717738493

Sørensen, M. (2006). Motivation for physical activity of psychiatric patients when physical activity was offered as part of treatment. Scandinavian Journal of Medicine and Science in Sports, 16(6), 391-8. https://doi.org/10.1111/j.1600-0838.2005.00514.x

Sørensen, M., Bentzen, M., \& Farholm, A. (2020). Lessons learned from a physical activity intervention in psychiatric treatment: Patient, staff, and leader perspectives. Frontiers in Psychiatry, 11, 87. https://doi.org/10.3389/fpsyt.2020.00087

Teixeira, P. J., Carraca, E. V., Markland, D., Silva, M. N., \& Ryan, R. M. (2012). Exercise, physical activity, and self-determination theory: A systematic review. International Journal of Behavioral Nutrition and Physical Activity, 9, 78. https://doi.org/10.1186/1479-5868-9-78

Thogersen-Ntoumani, C., \& Ntoumanis, N. (2006). The role of self-determined motivation in the understanding of exercise-related behaviours, cognitions and physical selfevaluations. Journal of Sports Sciences, 24, 393-404. https://doi.org/10.1080/02640410500131670

Thomas, C. (2004). How is disability understood? An examination of sociological approaches, Disability \& Society, 19:6, 569-583. https://doi.org/10.1080/0968759042000252506

Thompson, E. R. (2007). Development and validation of an internationally reliable shortform of the positive and negative Affect schedule (PANAS). Journal of Cross-Cultural Psychology, 38, 2, 227-242. https://doi.org/10.1177/0022022106297301

Treweek, S., \& Zwarenstein, M. (2009). Making trials matter: Pragmatic and explanatory trials and the problem of applicability. Trials, 1O(1), 1-9. https://doi.org/10.1186/17456215-10-37

Vancampfort, D., Firth, J., Schuch, F. B., Rosenbaum, S., Mugisha, J., Hallgren, M., ... \& Carvalho, A. F. (2017). Sedentary behavior and physical activity levels in people with schizophrenia, bipolar disorder and major depressive disorder: a global systematic 
review and meta-analysis. World Psychiatry, 16(3), 308-315.

https://doi.org/10.1002/wps.20458

Vancampfort, D., Rosenbaum, S., Probst, M., Connaughton, J., du Plessis, C., Yamamoto, T., \& Stubbs, B. (2016). What are the top 10 physical activity research questions in schizophrenia? Disability and Rehabilitation, 38, 2235-2243.

https://doi.org/10.1016/j.jad.2016.01.046

Vancampfort, D., Stubbs, B., Venigalla, S. K., \& Probst, M. (2015). Adopting and maintaining physical activity behaviours in people with severe mental illness: The importance of autonomous motivation. Preventive Medicine, 81, 216-220. https://doi.org/10.1016/j.ypmed.2015.09.006

World Health Organization. (2021). Physical inactivity: a global public health problem. NCDs | Physical Inactivity: a global public health problem (who.int).

WHO regional office for Europe (2019). Motion for your mind. Physical activity for mental health protection and care. Copenhagen, World Health Organization Regional Office for Europe.

(C) 2021 by the authors. Submitted for possible open access publication under the terms and conditions of the Creative Commons Attribution (CC BY) license (http://creativecommons.org/licenses/by/4.0/). 